DOI https://doi.org/10.36059/978-966-397-197-1/129-152

\title{
THE PECULIARITIES OF BANDURA SOUND PRODUCTION: THEORETICAL AND PRACTICAL ASPECTS
}

\section{Broiako Nadiia}

\section{INTRODUCTION}

The contemporary world cultural processes are defined by deep informatization of culture and artistic space, the interaction of different ethnic cultures and types of civilization (on grounds of mental, religious, and ideological identity) and at the same time, the aspiration of the peoples, ethnic groups and small-numbered ethnic groups for avoiding the "self-dissolution". The traditional basis of folklife culture brings forward the ethic culture.

In Ukraine, the revival of traditional music, kobza performance, and academic bandura art meet the contemporary art trends and criteria of the global values. Therefore, the training of a new generation of bandura players is necessary and well-timed. Bandura playing skills as the line of research for music performing arts are topical in the works of many scientists: N. Davydov, "Folk Instrument Performance History" ${ }^{1}$, N. Davydov "Kyiv Academic School of Folk Instrumental Art"2, V. Dudchak "Bandura Art of Ukrainian Emigre Community of the 20th Early 21st centuries"3, I. Zinkiv "The Bandura as a historical phenomenon"4, V. Kushpet "Traveling Musicians in Ukraine of the

${ }^{1}$ Davydov M.A. (2010) Istoriia vykonavstva na narodnykh instrumentakh [Folk Instrument Performance History]. Lutsk: Volyn Regional Printing House.

${ }^{2}$ Davydov M. (1998) Kyivska akademichna shkola narodno-instrumentalnoho mystetstva [Kyiv Academic School of Folk Instrumental Art]. Kyiv: Ukrainian National Music Academy Tchaikovsky.

3 Dudchak V. (2013) Bandurne mystetstvo ukrainskoho zarubizhzhia XX pochatku XXI stolittia: Monohrafiia [Bandura Art of Ukrainian Abroad of the 20th early 21st Century: Monograph]. Ivano-Frankivsk: Foliant.

${ }^{4}$ Zinkiv I. (2013) Bandura yak istorychnyi fenomen: Monohrafiia [The Bandura as a historical phenomenon: Monograph]. Kyiv: The Rylsky Institute of Art Studies, Folklore and Ethnology. 
$19^{\text {th }}$ - beginning 20th century", V. Kushpet "School of reconstruction of the performing tradition (kobza, lira, torban, bandura, singing)" ${ }^{16}$, V. Mishalov "Kharkiv bandura", A. Omelchenko "School of bandura playing" ${ }^{8}$, Y. Puchalski " The teaching technique of bandura playing"', M.Khai "Mykola Budnik and kobza art"10. These works, of course, are unique scientific tools in musical performing activities of banduraplayers as a system of concepts, terminology, methodology and techniques. The authors' concepts allow for many themes and interpretations with a view to their rational use for bandura art along with a revolutionary basis - on the basis of the in-depth study of the specifics of bandura sound production and phonation.

It should be noted that the publications about bandura genre in studies of the twentieth century (by the time of Independence) because of the ideological canons of the Soviet State was reduced to the identification of certain facts of professional education of bandura players, but did not give the optimal characteristics of this art as a unique authentic and academic artistic and technological mental thinking as a Ukrainian national identity factor in musical performance.

When the Soviet-era ideological guidelines in Ukrainian musicology were stopped, interest in the authentic musical tradition was renewed, and scientific interest in the high spiritual mission of the national musical instrument began to grow. Researcher N. Chernetska notes: "Bandura performance is a significant factor in the patriotic upbringing of young people, which is especially important in the process of forming national

${ }^{5}$ Kushpet V. (2007) Startsivstvo. Mandrivni spivtsi-muzykanty v Ukraini XIX pochatok XX storichchia [Eldership. Travelling Musicians in Ukraine the 19th beginning 20th century]. Kyiv: Tempora.

${ }^{6}$ Kushpet V. (2016) Shkola rekonstruktsii vykonavskoi tradytsii (kobza, lira, torban, bandura, spiv) [School of reconstruction of the performing tradition (kobza, lira, torban, bandura, singing)]. Kyiv: Tempora.

${ }^{7}$ Mishalov V. (2013) Kharkivska bandura: kulturolohichno-mystetski aspekty genezy i rozvytku vykonavstva na ukrainskomu narodnomu instrumenti [Kharkiv bandura: Cultural and Artistic Aspects of Genesis and Development of Performance on the Ukrainian Folk Instrument]. Kharkiv: Publisher Savchuk O. O.

${ }^{8}$ Omelchenko A. (1973) Shkola hry na banduri [A handbook for the bandura]. Kyiv: Muzychna Ukraina.

${ }^{9}$ Pukhalskii Ia. G. (1978) Metodika obucheniya igre na bandure [The technique of teaching bandura playing]. Kyiv: Goskonservatoriia.

10 Khai M. (2015) Mykola Budnyk i kobzarstvo [Mykola Budnyk and kobzarstvo]. Lviv: Astroliabiia. 
landmarks for the modern young generation and will in some way affect the content and structure regarding the values of Ukrainian society in the future". 11

At the same time, the in-depth disclosure of the mental nature of playing the bandura, like any kind of musical performance, requires recourse to its layers, laid in the thick of performing folk tradition, which has clearly defined features inherent in this original national instrument. Exploring the open environment of the musical space of the $20^{\text {th }}-21 \mathrm{st}$ centuries, V. Dorofeyeva notes: "The contemporary style space of Ukrainian academic music demonstrates a correlation between tradition and innovation. One of the leading features of the creativity of most composers is the free use of the achievements of the previous centuries,... and the main feature of the stylistic space of Ukraine is the appeal to new folkloristics, which is manifested in a type of modal tone complex". ${ }^{12}$ Academic bandura performance of today, being at the forefront of modern music-style trends, is deeply rooted in the traditional timbre and sound sphere. It is important to understand and analyze the theoretical performance aspects of bandura sound production and to find ways of practical implementation of sound images.

\section{Bandura Sound Production as a Means of Artistic Expression}

Understanding the problems involved in sound production is extremely relevant in the creative process of a musician of any speciality. Without mastery of the specific sound production on the instrument, it is impossible to achieve a clear, artistically perfect performance and complete reproduction of the artistic content of a musical work.

Researcher of related performing genre (Domra) O. Oliynyk, has carried out a number of scientific studies in the field of artistic and figurative intonation regarding instrumental sound, emphasizes: "In our time, instead of a permanent hierarchy of "artistic and self-sufficient applied creativity", variable orientations are put forward, layers and

${ }^{11}$ Chernetska N. (2018) Vykonavska tvorchist bandurystiv Volyni yak dzherelo formuvannia natsionalnoi samosvidomosti [Performing creativity of bandura players in Volyn as a source of formation of national consciousness]. Bulletin of the Kyiv National University of Culture and Arts. Series: Musical Art, vol. 1, p. 90.

${ }^{12}$ Dorofeeva V. (2016). Formuvannia suchasnoho muzychnoho stylovoho prostoru na prykladi tvorchosti ukrainskykh kompozytoriv [Formation of modern musical style space on the example of creativity of Ukrainian composers]. Muzychne mystetstvo i kultura [Music art and culture], vol. 23, p. 267. 
levels of artistic expression, which has led to the academicization of a number of genres and links in the popular music-creative practice, including playing folk instruments that have historically been formed in folk art in these countries, and only in the last decades, have they acquired a new artistic and aesthetic meaning and gradually entered the sphere of academic creativity and performance". 13

However, as evidenced by performance and pedagogical practices, there is still a widespread tendency among academic bandurists to underestimate the significance of sound production, which leads to impoverishment of the artistic and visual palette of the instrument and gives rise to misconceptions about its imperfect nature preventing it from engaging alongside such local classical solo instruments like the harp and guitar.

At the same time, the practical activities of leading concert performers, the experience of well-known Ukrainian bandura educators allow us to carry out a complex analysis of the instrumental specificity that underlies the whole process of forming the bandurists artistic technique.

Summarizing his rich performing and pedagogical experience, G. Neuhaus briefly formulated the principles of working on sound: "The first is the "artistic image"(i.e. meaning, meaning, expression, "what is it about"); secondly - sound in time - objectification, materialization of the "image" and, finally, thirdly - technique in general as a set of means necessary to solve an artistic task, playing the piano "as such", i.e .owning his musculoskeletal apparatus and mechanism instrument"14" This principle should be fundamental in the process of forming a brilliant instrumentalist.

Bandura sound production, in terms of auditory perception, like sound production on any other musical instrument, is characterized by the following basic properties: height, strength, duration and timbre. The understanding of sound production in the aesthetics of the performing arts is somewhat different than in acoustics. Here we are primarily referring to the quality of sound, its ability to serve as as a carrier of an

13 Oliinyk O. (2018) Domrove tremolo $\mathrm{v}$ aspekti rytorychnoho zmistu vykonavskykh pryiomiv hry [Domra Tremolo in Terms of the Performance Techniques Rhetoric Context]. Bulletin of the Kyiv National University of Culture and Arts. Series: Musical Art, vol. 1, p. 58.

14 Neuhaus G. (1988) Ob iskusstve fortepiannoi igry [On the Art of Piano Playing]. Moscow: Muzyka, p.69. 
artistic idea, and not so much as one, separate, or many groups of sounds, musical phrases, melodies. F. Chopin, paid considerable attention in his concert and pedagogical work to the quality of sound produced, and said that "as one word does not make a language, so one abstract sound does not make music". ${ }^{15}$

Sound production, as a primary means of artistic expression, is also an important element of individual performance style. It may be beautiful or not beautiful, soft or firm, gentle or dramatic. Depending on this, a bandura in the hands of a performer will cry or laugh, sing or growl, click, dance or console. In terms of the beauty regarding the sound produced, the most prominent bandurists of the 20th -21 st centuries received the highest praise and positive epithets - Hnat Khotkevych, Vasily Yemets, Hryhory Kytasty, Serhiy Bashtan, Alla Sheptytska, Petro Chukhrai, Volodymyr Yesypok, Halyna Menkush, Victor Mishalow, Roman Hrynkiv, Heorhiy Matviyiv, Serhiy Zakharets.

A bandura string is whimsical: plucking or hitting it in different places vertically - from the bridge to the pegs - we obtain a variety of sound colours. The reason for this is the inhomogeneous elasticity of the string. Near the bridge and upper peg box the string is "harder", the possibility of its deformation is much smaller, and therefore the oscillatory process that is set up in such a place, creates an original sound colour - "under the mute". In the middle of the string, it is much softer and subject to varying degrees of deformation, so it is at this point of excitement that we achieve the most dynamically bright and full sound regarding timbre.

While working on sound production is an important part of a professional musician's training, it should be remembered that a sound is an important tool, but not the primary purpose of performing. "What moves us as beautiful sound," says G. Neuhaus, "is actually something much more - it is the expressiveness of the performance, that is, the organization of the sound in the course of the performance of the work". ${ }^{16}$

In order the work on the sound production to be effective, the performer must understand the need to possess a beautiful, high-quality sound, clearly presenting in his mind the form of the sound, its colour,

${ }^{15}$ Milshtein Ia. I. (1967) Sovety Shopena pianistam [Chopin's advice to pianists]. Moscow: Muzyka, p. 19.

${ }^{16}$ Neuhaus G. (1988) Ob iskusstve fortepiannoi igry [On the Art of Piano Playing]. Moscow: Muzyka, p. 81. 
emotional load and sound-motion necessary in order to realize an artistic idea. Extremely interesting in this aspect is K. Martinsen's concept of "sound-production will", which can be formulated briefly as a continuous chain of artistic performances: I imagine - I perform - I hear. The outstanding researcher attaches particular importance to the indivisibility of the act of execution and the synthesis of its basic constituent elements: "Never can a spiritual impulse in itself be an element of creativity, just as musical hearing or a muscular system, be considered separately". ${ }^{17}$

The musical movement is born out of the interaction of the musicalperformance movement and the string. We consider sound-making movements to be methods of sound production on the bandura, among which the main ones are pluck and rest stroke. Next to the concept of "beautiful" sound production, there is a concept of "ugly" sound, which may be due to inconsistency and imperfection of the mechanical and physiological order. The main reason for poor sound quality may be an imperfect, or "dead" instrument, an inaccurate tuning system, the unregulated levers and switches of the retuning mechanism. But if mechanical defects can be eliminated relatively easily, problems of the physiological and artistic plan can be prevented by carefully polishing factors such as applicative orientation, understanding the arrangement of intervals chords on the strings, proximity of the fingers to the strings, the use of orientation-touching, auditory coordination in the representation on the basses and the main strings, and the rational use of hand weight. If a musical instrument materializes perfect sound images and, in the process enriching, updating the real world of sounds, forming new, more interesting musical-sound ideas, then the performer by his nature, his high artistic taste and intellect should become the life-giving creator and soul, filling the mechanical substance with a variety of emotions and feelings. Only in such a combination will the surrounding world and the essence of a human being in it be opened to us in the multidimensional sound space creating the artistic image of a musical work. The bandura performer's will, the "direct creators" of the bandura playing are the fingers, the parts that become mediators, the guides of the path from the performer's heart through the maze of strings and soundboard to the heart of the listener.

17 Martinsen K. (1977) Metodika individualnogo prepodavaniia igry na fortepiano [Methods of individual piano teaching]. Moscow: Muzyka, pp. 26-27. 
Overcoming the resistance of the strings determines the shape of the bandurist's movements, in which the methods of sound extraction, based on the span and weight of the hands, predominate to achieve volume. Bandurists need to train not only the muscles of the fingers, but also the wrists, forearms and shoulders, to specifically improve the control of the activities of the extensor muscles.

In general, the specificity of the bandura requires close contact of the artist's fingers with the strings. Therefore, before moving on to the development of various skills of contacting the hands with the strings, it is necessary to understand the bandura specifics of applicative orientation. Applicative orientation is the complex representation of the performer of harmoniously-harmonic relations regarding the extracted sounds, the formal structure of the construction of the finger movements on the strings and their coordination in the process of playing. There is a need for preliminary analysis of stringed row(s) because the same intervals and chords on different degrees of scale may have a completely different arrangement. A second in major only from the 3rd and 7th degree on the main row, and from the 1st, 2nd, 4th, 4th and 4th levels it is possible to play this interval only with the help of the strings of the upper row, which necessitates a change in the method of sound extraction or change of position of the playing apparatus.

Intonation problems that arise as a result of the design and construction features of the bandura give rise to a number of technical difficulties. Without comprehending the string row in its real "sounding" is a complicated reading of the notes from manuscript, transposition, hearing, improvisation. Particular attention should be paid to the bass due to the inability to use the left thumb. The performer must compensate for this disadvantage by actively using the fourth and fifth fingers. The first step to developing the orientation here is to memorize the order of the strings, which is facilitated by their small range (one octave), the specificity of cutting the upper nut, when the upper row produces a diatonic scale of $\mathrm{C}$ major, and the lower the additional chromatic notes.

To create a muscular sensation of the required distances, the applicative-auditory orientation it is useful to do silent exercises in the repeated easy permutation of the fingers on the strings with a clear understanding of the particular intervals. Such exercises activate the imagination of the performer, allows him to focus on the basics for orientation - the distances and directions of individual movements, as well as the internal auditory perception of sound, dynamic and other 
relationships. Real playing activates the performer's attention on the assessment of what he hears and what he does not, silence - on the lead of the playing, enhances the role of consciousness, subconscious and intuition. The proximity factor of the fingers on relation to the strings is related to their vertical position on the bandura, which ultimately leads to inconvenient visibility of the string rows and the lack of visibility of the working bass range. The tactile and orientational ability of the fingers must compensate for this lack of visibility. The continuity of such contact ensures reliability for their implementation and is one of the essential sides, which is a specific feature of the bandura technique. From this, it is easy to understand the importance of developing the activity of the bandurist in controlling the movement of the muscles, including those of the fingers and the wrist. A significant role for both single and double notes, octaves, chords is played by the transverse and longitudinal movements of the fingers and hands, the placement of the thumb, as well as the narrowing and stretching of the wrist.

One of the conditions for playing reliability is the feeling of continuous contact of the bandurist's fingers with the strings. Extremely valuable and innovative is the studies by Y. Pukhalsky in bandura methodology and the concept of preparatory playing movement: «the purpose of preparatory movements of fingers, hands, forearms of the player - to ensure the error-free playing of necessary strings; and on the other hand, these preparatory movements should provide the necessary repetition". 18

Therefore, preparatory playing movements can be considered as an element of staging, which effectively allows the process of sound production. Since musical performance is not possible without a clear organization of playing movements, the important role played by preparatory movements in the process of artistic sound production is obvious. The author distinguishes the following types of preparatory movements:

- the fingers are pre-installed directly on the strings;

- the fingers are pre-positioned above the desired strings at some distance from them;

- fingers are appropriately positioned (opened) when moving the hands over the strings. The performer is confronted with this kind of

${ }^{18}$ Pukhalskii Ia. G. (1978) Metodika obucheniya igre na bandure [The technique of teaching bandura playing]. Kyiv: Goskonservatoriia, p. 48. 
preparatory movements when performing individual sounds or harmonies, located at a considerable distance. ${ }^{\text {.9 }}$

It is necessary to develop the skill of feeling the finger as a starting touchpoint for subsequent movements. An unreasonable detachment of the hand from the string row breaks the tactile communication in the movement, leading to errors, particularly harmful during the period of learning the work. These inaccuracies of the initial movements subsequently lead to an "unclean" sound.

A very important point is the training of focus simultaneously in different planes. The task is to control the parallel movement of two hands. The variant method is effective: the focus is alternately on the bass, then on the treble strings. Focusing on one area of activity does not mean ignoring the other completely. Translated into the background, the left hand is involuntarily controlled, sometimes to a greater extent than the right.

A characteristic feature of diversified attention is the uneven intensity of nervous energy. Outstanding performance cannot be controlled at the same time with the same quality. If we focused our attention on one object, then the phenomena, objects, and actions that surround us are controlled by the "accompanying waves" of nerve energy in another plane.

In the course of playing there is another feature worthy of attention the periodic involuntary transition of the first plan of attention to the second and vice versa, and the second - to the first. In accordance with this pattern, it is advisable to vary the focus of the auditory-motor imagination alternately on the bass, and then on the treble strings. As an auxiliary, the variability of audio-motor sensations is used, for example, an unequal juxtaposition of bass and fringe depth of sound, strokes, weight sensations, etc. The importance of orientation skills and techniques in the acquisition of techniques of artistic performance is that they are the key to selecting appropriate, rational movements for clean and accurate performance.

Psychophysiological patterns of performing motor skills on stringplucked instruments, unfortunately, are not covered in the methodological literature and are an indispensable area for the study and creation of a voluminous picture of the application of scientific knowledge of

${ }^{19}$ Pukhalskii Ia. G. (1978) Metodika obucheniya igre na bandure [The technique of teaching bandura playing]. Kyiv: Goskonservatoriia,p. 49. 
psychophysiology in music and the performing arts. During the study of the particular work and mastering the whole technical complex, the performer focuses on other essential aspects of his skill.

When used rationally, the weight playing provides the following tactile-motor sensations and muscular reactions: the support of the finger pads on the string; the feeling of overcoming the resistance of the string; saving energy and magnitude of movements in muscular pulsation; readiness of the finger for the next pluck, stroke; continuity of serial communication of sound in passages. Weight play is the basic feeling on which the natural organization of the locomotor system as a whole is formed because it promotes the proper functioning of the parts of the arm and muscular system, the coordination of their work.

Care should be taken to ensure that the weight of the hand is distributed evenly across all fingers. It is more difficult to feel when applying the thumb. While performing the passage, the sensation of weight should not stop on any string. Work in this regard can be considered complete if you can "place" your hand in the passage. Weight play nurtures reliability, the confidence of execution, the timidity of the string row disappears, automaticity of movements is developed - a necessary condition for artistic performance. To bring the skill of the weight playing to perfection, each piece of the work, where the continuity, fluidity of the weight sensation, need to be played several times, seeking a total, continuous collection of the sound is necessary. As you master the technique, the need for a special setup for the weight playing is eliminated. There remains a positive sense of naturally organized and appropriate contact with the string.

But no matter how effective this or that method of refining sound is, its ultimate goal is automation, bringing movements into the realm of the subconscious. In the case of prolonged work in the weight playing one can also be observed negative phenomena: fatigue, loss of muscle ability, exclusion of figurative thinking. Similar effects are inevitable when this method becomes an end in itself, when muscle pulsation is not controlled when applied.

Bandura playing should use the appropriate measure of hand weight, which will be sufficient to overcome the resistance of the string. Finger weights are, of course, sufficient when performing notes of short durations. To achieve the long-lasting sound of thirds, sixths, octaves, chords, it is necessary to use other parts of the playing apparatus: the muscular system of the shoulder girdle, shoulder, elbow and wrist joints. 
They need to be integrated, in whole or in part, into the sound-making process in the case of artistic expediency.

In I.E. Koch's work "The Basics of Stage Movement" a classification of movements is made up, which includes five groups: general, working, semantic (related), illustrative, pantomime. ${ }^{20}$ The music-playing process includes, the first and secondary, as well as illustrative and pantomime movements, which manifest themselves spontaneously, and therefore cannot be a goal in the development of the bandura player's performing technique. We are primarily interested in working movements because they are at the heart of the formation of bandura sound.

A prerequisite for improving coordination in all its varieties is the auditory-motor representation. It gives impetus to expedient, controlled playing movements. In the initial period of study, the student perceives the musical text mostly visually or by ear. Kinematic expedient reflexivity is not yet developed. This leads to breakdowns. Coordination of movements is often hindered by the difference in the development of the left arm of the bandura player from the right.

The concept of "weighted playing" means economizing the energy in the muscles of the fingers and hand by using the weight above the upper arms. The use of this weighting method on the bandura is sometimes questionable: can the hand weight be used when the strings are almost vertical as opposed to gravity? The sensation of the weight of the hand on the vertical plane is achieved by the grasping, sliding, gripping movement of the tips of the finger (lateral part) into the palm. If on the horizontal plane, the weight of the armrests on the arch formed by the finger between the nail and the wrist phalanges, with an equal load on both these points, then the vertical position plays the role of this support by the gripping movement of the tip of the finger and nail phalanx.

As for weight as a factor in achieving a particular volume, it directly affects the amplitude of the oscillation of the string. The effectiveness of the method of weight play on the bandura is determined not only by the achievement of the volume of sound, but also by establishing the naturalness of consistent.

Coordination is the result of specially organized labour. Its formation is facilitated by the principles of consistent mastering of technical difficulties from the simple to the complex, as well as the method of

${ }^{20}$ Kokh I. E. (1970) Osnovy stcenicheskogo dvizheniia [The Basics of the Stage Movement]. Leningrad: Iskusstvo 
dividing up complex technical tasks into simpler components. The first step to developing coordination is training in purposeful management of one's muscular condition (active-passive). The artist must learn to subtly feel and use exactly the minimum energy required to solve a particular artistic task. Coordination requires long, painstaking work and many exercises.

Particular attention should be paid to improving the bifunctionality of left-hand movements. The inconvenience of fingering and the exceptionally tangible manner of orienting the fingers on the bass strings forces the bandura player to constantly distribute attention between the comprehensive (logical, scalic-harmonic, applicative fingering, type of stroke) comprehension of the structure and perfect mastery of the skills and techniques of finger movements. By combining different types of movements within a holistic complex, it is necessary to focus on preserving and improving those skills and muscular reactions that were previously learned as appropriate for the implementation of this task. Therefore, multidimensional attention is needed. A method for shifting attention from one movement to another is very effective. For example, from the bass to treble strings, from one stroke to another, etc. This allows us to define the broad concept of coordination in the musicperformance process as a unity of feelings, thoughts and movements.

Sound production mastery is the ability to hear and shape it from the moment of attack to its end. That is why the bandurists' special concern is the technique of "pure" production of sound devoid of nail noise. It is possible to achieve this level of performing technique by applying the pre-positioning of the fingertip on the string. The finger supported by the finger pad will prevent unpleasant "buzzing" arising from the friction between the metal and the nail. The nature and duration of the sound of the bandura depend mainly on the moment of the excitation of the string, after which the gradually decaying sound is not possible for the performer to change its dynamics (except for the tremolo mode). Therefore, not only the melodic line, but also the passages should be richer and more flexible (more exaggerated than in other instruments) in order to clearly convey the intonation of the music being played.

Sometimes the incongruence of the playing apparatus with auditory control leads to hypertrophied nuance, resulting in noise. As a result, performers should always remember that even in the most emotional, dynamic and loud episodes, care must be taken to ensure that the sound produced from the bandura remains aesthetically beautiful, and noble. 
Therefore, one of the main tasks for a bandurist is to produce a deep, capable of the most nuanced, "vocal" sound with all of its innumerable gradations, which is an important factor in the formation of a highly professional bandura performer.

\section{Peculiarities of Bandura Technique Formation}

One of the leading expressive means that dominates the artist's arsenal is the stroke. As a result, during the entire historical period regarding the development of professional bandura performance, the attention of performers, researchers, and methodologists was drawn to the problem of finger stroke technique. The scientific and methodological literature for the bandura has not yet created a system of common terms for different types of strokes. The conceptual certainty in the stroke terminology will contribute to the adequate realization of the composer's design, as well as the formation of a bright individual manner of the performer, because it is related to the choice of strokes. The individual manner of fingering determines the creative face of the interpreter. The complexity and multidimensionality of this problem lead to an attempt to classify bandura strokes, to find a unified approach to their systematization on specific grounds.

In musicology, the concept of "stroke" (germ. - Strich - trait or stroke) since the description of "strokes of the bow" by L. Auer has undergone a considerable evolution, until it was defined, first of all, as an artistic phenomenon, which is achieved by appropriate technical means.

It should be emphasized that an individual sound, whatever its characteristic form, is not a carrier of tone content. Only in the combination (through transients) of two or more sounds that have similar or different characteristic forms, can a performer unlock the interpretation. Without claiming comprehensive coverage of the issue, let us try to determine the basic principles of classification of bandura strokes.

Analyzing the performance and pedagogical experience, as well as the stroke symbolism in the music literature, we define the system of strokes according to M. Davydov, which consists of two main groups: strokes with different nature of connectedness and separation of sound (legatimo, legato, non-legato, staccato, staccatimo); strokes with different character of sound attack (detache, marcato, sforzando, portamento, portato). The conditionality of the distribution of strokes into groups is quite obvious. First, in real sound, both connected and separate execution is impossible 
without the nature of the attack. The nature of the sound attack depends on the degree of impact on the string. A number of sounds made non-legato piano first, then followed by forte, in the first case will have a softer, and in the second - a clearer, more emphasized attack. Thus, according to the classification we have adopted, the same method of separate execution is practically given two separate stroke names. One of them characterizes the kind of connection of sounds, the other has a dynamic meaning, for example: non-legato - detache; non-legato - marcato; non-legato sforzando and others. Secondly, in the process of performing by organic combination of various dynamic articulatory-rhythmic and timbral means on the bandura, as well as on other instruments, there is an unlimited number of stroke shades. The list of these bandura strokes, which have been widely used in practice, should not be considered as a mechanical transfer to the bandura of piano or violin techniques. The common terminology is used here to refer to the nature of expressive means in specific instrumental conditions.

As a result of the natural ability to play the bandura, the dominant role in bandura articulation is the legato stroke. The term legato means a smooth, continuous, "fused" performance of individual sounds, in which each note of the melody is most fully sustained. If on most instruments (piano, violin, domra, bayan) the previous sound is discontinued at the moment of taking the next one (due to articulation), then on the bandura the previous sound "continues" at the moment of taking the next one. The specific fineness of the extracted sound, when the string, without a special muffling motion, vibrating and damping naturally, creates a different nature to the banding nature of the bandura. Legato is the main articulation colour on the bandura. As noted above, when performing a passage on the bandura from the technical side, it is impossible to cut off the previous sound, so the articulatory clarity in combination with the appropriate accentuation (according to the dynamic contours of the melody) of the next sound becomes especially important.

The most acceptable form of motion is legiero. The basic conditions of execution are the followings: independence of fingers and their timely readiness to pluck a string, obligatory resting of a finger on a string before the pluck, maintaining in the bundle the constant sensibility necessary for the "creating" and at the same time of a sensory attack. This specific sensuality is associated with the feeling of lightweight coming from the direct support of the fingers - the wrist; coordination with a free but assembled, ready-to-use wrist; a stronger colour requires the support of a larger source of strength - the forearm and shoulder; the 
constant desire for ever faster pre-positioning of the fingers on the strings and the economy of the preparatory movements; continuous activation of auditory attention aimed at matching the volume of the extracted sound with the expressive content of the melody.

If the passages performed legato sound lightly on the bandura, pearly and at the same time soft, "velvety", it is difficult to obtain legato due to the natural gradual attenuation of each sound at a very slow tempo, as well as when performing longer-scale durations.

Legatissimo on the bandura - an expression of the ultimate fusion of performance, different from a slightly deeper sound flow and softened attack. The implementation on the bandura of legitissimo is directly dependent on the duration of sound, tempo and dynamics.

At a slow tempo, the natural damping of the string vibration makes it impossible to touch adjacent sounds, as in the case of longer-scale durations. Large dynamic gradations require lightning attacks, and as a result, sound injections that destroy the fusion of sound.

Therefore, the use of this touch is appropriate for improving the flight, singing sound, which increases the direction of the passage to a certain point, enhances the pedaling of the overall sound, and helps to integrate the integrity of the embodiment of melodic constructions. Improving the performance in legitimo, it is necessary to develop the elastic mobility of the fingertips. Hand, wrist and fingers should be absolutely light, free and supple. The pads of the fingers, dig deep into the strings with a lightweight, "intangible" finger weight, are resilient but softly set the strings vibrating. Carl Czerny's view that "in the musical of performance legato is the rule is, all other means are exceptions," can serve as a credo of bandura stroke technique.

Strokes with a distinctive sound can be firmly classified in bandura technique to the category of exceptions. If most instruments achieve staccato with the cessation of the sound-producing action (breathing, movement of the bellows, the interaction of the finger with the keys, movement of the bow, etc.), the bandura staccato requires additional movement in order to stop the vibration of the string. The bandura staccato is a sound burst that is achieved by a sharp attack and muffling (if necessary - immediately) of the string. Bandura staccato has two varieties - finger and wrist, and is determined by the nature of the work, its texture and tempo. The finger staccato is used for extraction of blatant sounds, it is made by light, mobile and elastic fingers. The playing finger is restrained into the string before the sound extraction by the tip of the finger; the string "breaks" with a pinch or blow easily but firmly; the 
adjacent finger quickly covers the vibrating string with the tip. In this way, the staccato provides sound volume, economy, accuracy, the precision of movements, promotes evasion, effective at a fast pace and various dynamic gradations in a single note writing. The wrist staccato is used in the performance of thirds, sixths, octaves and chords. The hand and wrist are completely free, supple, and ready for action. The nonplaying fingers are barely raised, the playing fingers (in accordance with the dynamics) are tufted more or less into the strings. A pluck (or strike) is made with a repulsive movement, the brush easily flies (bounces) over the strings with one continuous, smooth and directional movement and drops with the fingertips on the vibrating strings.

If the staccato is peculiar to some degree of brevity, acuity, suddenness, fragmentation of sound, then non legato is seclusion, greater sympathy, it can be classified as an extended staccato. Endurance duration and caesura may vary depending on the artist's artistic intentions. The bandura non-legato is used to emphasize sound resilience, is used in works of energetic, assertive, or soulful, thoughtful nature, and certainly enriches bandura sound resources.

Creative practice demonstrates that within the performing process there exists a mutual influence between these skills. It is known that all varieties of staccato are characterized by dashedness, isolation and that for legato -we have the coherence of the sound line. This, however, does not mean a complete absence of common features, both in manner and in the way of embodying allegedly opposite articulatory shades: the element of connectedness in the separate sounds of non-legato and staccato on the one hand, and the element of resolution in the legatissimo and legato - on the other side. A connection is manifested in the generalized nature of the motion (equal, accelerating, decelerating). The cohesive motion resolution is manifested in the even dashed character of the attack of the sounds that make up the dashed line. The interpenetration of the character of the sound of the strokes suggests that there is no endless boundary also in the technical methods of execution between the legato and the staccato, to legitissimo and non-legato. Undoubtedly, a similar technique of sound extraction - elastic and accurate plucks or hits-by bandurist uses both legato and staccato in their playing. The difference is in the length of duration. Both legato and staccato require rapid, pluck-independent, finger movements. Both techniques involve the positional preparation of the fingers at the time of plucking or impact. The only difference is that the legato requires only sound-producing movements, and the staccato also requires the damping 
movements of the fingers (or the side of the palm) by which the sounds are stopped.

Speed, velocity, independence of movement of the fingers include the accuracy of attack coming from the playing of staccato, and consistency as an element of connectivity - from the legato. So, with the acceleration of the tempo, we observe the interpenetration of elements, legato and staccato. The maximum staccato speed is made possible by the unity of the movements generated by the legato. Conversely, a movable legato with a characteristic elasticity of attack is possible with sufficient clarity, which is used in the staccato.

The term detache, which means "separate", "detached", is used to refer to the sound production of single sounds with a soft attack. The stroke is borrowed from the practice of playing stringed instruments, where it means the extraction of sounds by individual smooth movements of the bow. Paying attention to the characteristics of the stroke on the technical side of the performance, should not be ignored most importantly - the smoothness of movement, which is associated with a gentle manner of attack and determines the artistic value of this stroke on both the violin and the bandura. Unlike the cohesive legato, when performing detache, individual sounds are separated by the muting movements of the tips of the oscillating vibrating string. This distribution is accompanied by the inevitable, almost imperceptible pause. The detail on the bandura includes three elements: a soft dipping of the finger into the bottom of the string; soft repulsion from the string by the pluck; muffling by the fingertip of the vibrating string. The main point is the accentuation achieved by the expedient activity of the fingertips, and the weight playing, which created the pressure on the string to give it the necessary dense vibration. Lack of coordination leads to sharp accentuation, to the "breaking" of the string.

The reception of detache is a complex collection of movements, which are coordinated and similar in character but different in energy consumption and movement. The muscles of the fingers and hands that perform the sound-producing function pulse more vigorously, more diversely than when performing the pausing action. Mastering the stroke requires prolonged slow-speed repetition, while maintaining strict auditory-motor control. Marcato - stressed solid attack. The mark of the marcato is intended for use. purposefully and reasonably directed energy concentrated in the attack of the sound. In the forte or fortissimo mode, the clarity of the attack of individual sounds corresponds to the desired quality of marcato. However, playing the piano in this way requires 
a softer attack. The marcato technique requires the fingertips to be rigid, providing an energetic pluck (or hit) from the tip of the nail. The stressed attack requires the pre-positioning of the fingers with the tips on the strings. This will help to avoid nail tones, "buzzing" of strings, and the attack will become more specific. The repetition of the stroke requires the repetition of a set of movements. When you change the dynamics, the nature of the hand remains, the only difference will be the intensity of muscle pulsation. Thanks to this, at any dynamic level (from pianissimo to fortissimo), the stroke gives the sound of activity. The stroke of marcato is used in music of solemn, energetic, heroic, marching or dancing character, an example is M. Dremliuha's "Poema-Rhapsodia".

The use of sforzando indicates the need for the enhanced dynamic accentuation of individual sounds. This effect is borrowed from the orchestral manner of highlighting by using the "tutti" at the beginning of the duration and keeping the sound for the part of the duration that remains with only one group of instruments (for example, woodwinds). The bandura sforzando, as an active highlight of the attack with the subsequent damping of sound, is used with different dynamics and may have different shades: sforzando-piano, sforzando-forte and others. This stroke requires a certain minimum sound duration, which would allow the two levels of sound volume to be compared. The difference between the attack and the sound of the main part of the duration is minimal, conditionally measured by one step of conventional dynamic gradations. With a general piano attack, a mezzo piano is obtained. The bandura sforzando, made by a blow or a pinch, sounds bright and colourful. It is known that the excitation of the string by the nail (plectrum) produces many rapid oscillations of short waves, which determine the sharper timbre. Therefore, to achieve accentuation of the pluck or stroke must be performed with nail support. This will provide the effect of a "lightning bolt" followed by a gradual natural decay of volume. Thus, the main task of reproducing the sforzando and its dynamic and agogic hues related to the nature of the attack rests on the firmness and at the same time the elasticity of the fingers. To master this stroke, the player should train at a slow tempo, seeking the sharpness of muscular reactions, accurate dosage of strength and duration of the accentuated part of the sound in various dynamics. At the same time, the technique of muscle relaxation should be improved at the correct moment. All this is varied both in dynamics and muscle tone, the work of the lower periphery should be carried out against the background of expedient application of weight playing and economy of the amplitude of movements. Sforzando is 
widely used as a means of emphasizing a coherent melody or individual sounds against another texture.

In addition to the types of connected and separate articulations discussed above, one of the most difficult strokes - portamento, deserves special attention. It reflected and combined the basic contradiction that is the driving force of all articulation processes, namely: the contradiction between the two extreme poles of pronunciation - connectivity and resolution.

Portamento on a bandura means a combination of finishing detache, marcato or staccato (sforzando) in a single semantic group with a maximum endurance of the lengths. Therefore, portamento does not refer to individual sounds but to a group of notes as an expression of a particular musical thought. There are various shades of portamento on the bandura: soft, delicate, decisive, grotesque or sharply emphasized, sharp and so on. Most often, this stroke occurs at a moderate and slow pace, which allows you to bring to the listener a full range of articulatory-dynamic gradations characteristic of a particular nuance of portamento. Portamento - a combination of soft attack sounds in a single phrase. The highest sound power on the bandura is achieved at the time of the sound attack (except for tremolo), so the soft pulsating attack at the realization of this stroke ensures the separation of sound, and the vibration of uncovered strings creates a sound fusion. Reception involves the unity of the following movements: the fingers are soft and at the same time firmly dipped into the strings; the strings are given the direction of oscillation in the plane of the line in parallel to the soundboard, with an elastic repulsive movement. The moment of repulsion from the string is dominant in the inertial movement of the hand - a soft, "spring" pinch causes a single smooth "breathing", the coordination of movements of the hand, forearm, the whole apparatus, as well as the appropriate sense of weight, which provides proper contact with the pads.

It is clear that the above principles of applying strokes to the disclosure of artistic image should not be taken literally, because they are directly dependent on the articulatory aesthetics of the particular work performed. But to determine that in the keyboard performance of the Baroque era was dominated by the non-legato, and in early Viennese classicism staccato, and that the articulation of romanticism is characterized mainly by the principle of connected playing, then this does not mean the need to impoverish the articulatory-stroke reducing it to a single type. On the contrary, such an understanding should diversify 
the use of the same touch when interpreting the music of different historical periods and artistic directions. Thus, in the baroque legato, there will always be an element of limitation of each sound, in the passages of Mozart, played with legitimacy, the articulatory clarity of the rhythmic pulse of the smallest duration will be preserved, in the romantic staccato -it is the singing of the tone.

Such awareness of stroke, as a complex sound-forming complex, should underlie the modern solution of the articulatory-barrier problems of bandura pedagogy and performance.

The stroke area is not only limited to articulation, that is, horizontal, but also covers the vertical: dynamics, the internal rhythm of expressive means, and timbre-articulation sphere. Each of these expressive means within the stroke has its original (stroke) characteristic detection. The characteristic aspect of articulation, dynamics, internal rhythmic of expressive means, timbre and acoustic effects underlies the differentiation of strokes not only on the basis of "connected separately" or "extended - short", but also on the signs: soft, active, phonetic, in a certain rhythm-intonation, timbre, etc. It is on this basis that bandura strokes crystallize into a rich palette of varieties: attack, separate, connected, legato-based, connection-separated when shaking

The completeness and content of each stroke, as an artistic phenomenon, is determined not only by one feature, but by the unity of expediently directed, concentrated expressive means, which characterizes it as an embryo of specifically spoken music, which includes, in addition to the mentioned qualities, also metrorhythm, and the dynamics of the process development. Thus, the term as a synthetic term is wider, more content than the articulation of binding and separation of sounds.

The methodological basis for the classification of strokes is the dialectical unity of a set of sound expressive means - articulation, dynamics, internal rhythm and timbre in strokes. Thus, the complex concentrates on the artistic and expressive qualities of the sound of the bandura.

\section{CONCLUSIONS}

Summarizing the results of the proposed study, we have outlined the following positions:

- complete detection of the content of the performed work, its character, style features can only be reproduced by having an arsenal of expressive means of performance, namely: intonation, dynamics, timbre, fingering, strokes; 
- the sound of the bandura, as defined by artistic quality, is found to affect the hearing volume and mass attained at t- a number of practical recommendations are given on forming the skills of concentration of attention on different planes of the instrument he time of the attack;

- a comprehensive approach to the formation of a multidimensional view of the bandurist technique is proposed. This complex includes: rational use of hand weight; applicative orientation; understanding the arrangement of intervals and chords on a string; development of orientation-touch communications; systematic applicative-auditory coordination in the representation of bass and main string;

- the technique of mastering cohesive and separate strokes on bandura as a means of artistic expression is proposed; the touches concentrate on the distinctive qualities of bandura sound as a result of a set of basic techniques, skills and abilities; the performance of melodic lines should not be performed outside the specified line colour; ability to listen and make voices as solid dashed lines - one of the most important tasks of forming the professional skills of a performer; performing technique in the broadest, most general sense and in all the variety of individual techniques, skills and abilities is a phenomenon of the artistic.

Therefore, one of the main tasks for a bandura player is to produce a deep, capable to the maximum possible nuance of "vocal" sound with all its innumerable gradations, which is an important factor in the formation of a highly professional bandura performer. Bandura technique does not exist outside the interpretation of the artistic content of the performed music piece.

Outlined issues are not limited to the proposed study. It is especially relevant at the stage of dynamic development of the modern music space, and therefore needs further scientific research.

- The technique of mastering the bandura connected and separate pickings as a means of artistic expression is proposed; there are the distinctive qualities of bandura sound in the pickings as a result of a set of basic techniques, skills and abilities; the performance of melody lines should not be performed outside the given pickings; listening and sound skills to perform single picking line is one of the most important tasks of forming a professional skill of the performer; performing technique in the broadest, most general sense and in all the variety of individual techniques, skills and abilities is art.

Therefore, one of the main tasks of a bandura player is to provide a deep, capable to the maximum possible shading of "vocal" sound with all its innumerable gradations, which is an important factor in the formation 
of a highly professional bandura player. Bandurist technique does not exist outside the interpretation of the artistic content of the performed musical work.

Outlined issues are not limited to the proposed study. It is particularly topical at the stage of dynamic development of the modern music space and therefore requires further scientific research.

\section{SUMMARY}

Understanding the phenomenon of bandura art, the evolution of the basic laws of the acoustic capabilities of the instrument and features of sound production, an awareness of the principles, forms and methods of education of bandura professional, are urgent questions of scientific research of today. The purpose of the study is to theoretically substantiate the performance aspects of bandura sound production, which, due to historical and cultural characteristics, rely on the academic performance model.

The methodology of the research is based on the application of musicological, analytical and performer-interpreting approaches. Scientific novelty lies in the complex coverage on the basis of scientific and theoretical understanding of the sound-forming processes of formation of the bandura player's mastery.

The research has made the scientific-theoretical analysis of the processes of forming the bandurist's mastery. On the basis of generalization of his own practical concert-performing and pedagogical experience, psychophysiological aspects of the bandurist's performing technique were revealed, a detailed analysis of the sound-making and sound-production on the banur was performed, the articulation and stroke means of the bandurist's performing skill were investigated.

\section{REFERENCES}

1. Chernetska N. (2018) Vykonavska tvorchist bandurystiv Volyni yak dzherelo formuvannia natsionalnoi samosvidomosti [Performing creativity of bandura players in Volyn as a source of formation of national consciousness]. Bulletin of the Kyiv National University of Culture and Arts. Series: Musical Art, vol. 1, pp. 90-100 DOI: https://doi.org/10.31866/2616-7581.1.2018.146253.

2. Davydov M. (1998) Kyivska akademichna shkola narodnoinstrumentalnoho mystetstva [Kyiv Academic School of Folk Instrumental Art]. Kyiv: Ukrainian National Music Academy Tchaikovsky. (in Ukrainian) 
3. Davydov M.A. (2010) Istoriia vykonavstva na narodnykh instrumentakh [Folk Instrument Performance History]. Lutsk: Volyn Regional Printing House. (in Ukrainian)

4. Dorofeeva V. (2016). Formuvannia suchasnoho muzychnoho stylovoho prostoru na prykladi tvorchosti ukrainskykh kompozytoriv [Formation of modern musical style space on the example of the creativity of Ukrainian composers]. Muzychne mystetstvo $i$ kultura [Music art and culture], vol. 23, pp. 260-268. DOI:https://doi.org/https://doi.org/ 10.31723/2524-0447-2016-23-260-268.

5. Dudchak V. (2013) Bandurne mystetstvo ukrainskoho zarubizhzhia XX - pochatku XXI stolittia: Monohrafiia [Bandura Art of Ukrainian Abroad of the 20th - early 21st Century: Monograph]. IvanoFrankivsk: Foliant. (in Ukrainian)

6. Khai M. (2015) Mykola Budnyk i kobzarstvo [Mykola Budnyk and kobzarstvo]. Lviv: Astroliabiia. (in Ukrainian)

7. Kokh I. E. (1970) Osnovy stcenicheskogo dvizheniia [The Basics of the Stage Movement]. Leningrad: Iskusstvo. (in Russian)

8. Kushpet V. (2007) Startsivstvo. Mandrivni spivtsi-muzykanty $v$ Ukraini XIX - pochatok XX storichchia [Eldership. Travelling Musicians in Ukraine the 19th - beginning 20th century]. Kyiv: Tempora. (in Ukrainian)

9. Kushpet V. (2016) Shkola rekonstruktsii vykonavskoi tradytsii (kobza, lira, torban, bandura, spiv) [School of reconstruction of the performing tradition (kobza, lira, torban, bandura, singing)]. Kyiv: Tempora. (in Ukrainian)

10. Martinsen K. (1977) Metodika individualnogo prepodavaniia igry na fortepiano [Methods of individual piano teaching]. Moscow: Muzyka. (in Russian)

11. Milshtein Ia. I. (1967) Sovety Shopena pianistam [Chopin's advice to pianists]. Moscow: Muzyka. (in Russian)

12. Mishalov V. (2013) Kharkivska bandura: kulturolohichnomystetski aspekty genezy $i$ rozvytku vykonavstva na ukrainskomu narodnomu instrumenti [Kharkiv bandura: Cultural and Artistic Aspects of Genesis and Development of Performance on the Ukrainian Folk Instrument]. Kharkiv: Publisher Savchuk O. O. (in Ukrainian)

13. Neuhaus G. (1988) Ob iskusstve fortepiannoi igry [On the Art of Piano Playing]. Moscow: Muzyka. (in Russian)

14. Oliinyk O. (2018) Domrove tremolo v aspekti rytorychnoho zmistu vykonavskykh pryiomiv hry [Domra Tremolo in Terms of the Performance Techniques Rhetoric Context]. Bulletin of the Kyiv National 
University of Culture and Arts. Series: Musical Art, vol. 1, pp. 57-66. DOI: https://doi.org/10.31866/2616-7581.1.2018.140573.

15. Omelchenko A. (1973) Shkola hry na banduri [A handbook for the bandura]. Kyiv: Muzychna Ukraina. (in Ukrainian)

16.Pukhalskii Ia. G. (1978) Metodika obucheniya igre na bandure [The technique of teaching bandura playing]. Kyiv: Goskonservatoriia. (in Russian)

17.Zinkiv I. (2013) Bandura yak istorychnyi fenomen: Monohrafiia [The Bandura as a historical phenomenon: Monograph]. Kyiv: The Rylsky Institute of Art Studies, Folklore and Ethnology. (in Ukrainian)

Information about the author: Broiako Nadiia, orcid.org/0000-0001-9109-1734 PhD in Arts, Professor Kyiv National University of Culture and Arts 36, Ye. Konovaltsia Str., Kyiv, 01133, Ukraine 